Microscopy of Materials 


\section{Microscopy of Materials}

Modern Imaging Methods Using Electron, $X$-ray and Ion Beams

D. K. Bowen

Department of Engineering

C. R. Hall

Department of Physics,

University of Warwick 
(C) D. K. Bowen and C. R. Hall 1975

Softcover reprint of the hardcover 1st edition 1975

All rights reserved. No part of this publication may be reproduced or transmitted, in any form or by any means, without permission

First published 1975 by THE MACMILLAN PRESS LTD London and Basingstoke Associated companies in New York Dublin Melbourne Johannesburg and Madras

SBN 333154959 (hard cover) 333187032 (paper cover)

ISBN 978-0-333-18703-6

ISBN 978-1-349-15601-6 (eBook)

DOI 10.1007/978-1-349-15601-6

This book is sold subject to the standard conditions of the Net Book Agreement.

The paperback edition of this book is sold subject to the condition that it shall not, by way of trade or otherwise, be lent, re-sold, hired out, or otherwise circulated without the publisher's prior consent in any form of binding or cover other than that in which it is published and without a similar condition including this condition being imposed on the subsequent purchaser. 


\section{Contents}

1. The Study of Microstructure 1

1.1 Optical Microscopy 2

1.2 Diffraction Techniques 3

$\begin{array}{ll}\text { 1.3 Modern Imaging Methods } & 7\end{array}$

1.4 Guide to Preliminary Reading 10

2. Scanning Electron Microscopy 13

2.1 Principles of Operation $\quad 13$

$\begin{array}{ll}2.2 \text { Specimen Preparation } & 17\end{array}$

2.3 Design and Construction of the Microscope 18

2.4 The Performance of the SEM 30

2.5 Electron Beam/Specimen Interactions: Contrast 37

2.6 Some Applications of Scanning Electron Microscopy 52

2.7 Image Processing $\quad 63$

2.8 Guide to Further Reading 66

3. Microanalysis $\quad 68$

3.1 Principles and Basic Design of Microanalytical Instruments 69

$\begin{array}{ll}\text { 3.2 Specimen Preparation } & 74\end{array}$

3.3 Design of the Electron Microprobe $\quad 80$

3.4 Combination Instruments 90

3.5 Quantitative Analysis with the Electron Microprobe 91

3.6 Comparison of Microanalytical Techniques 98

3.7 Some Applications of Microanalysis 101

$\begin{array}{ll}3.8 \text { Guide to Further Reading } & 112\end{array}$

4. The Electron Microscope 116

$\begin{array}{ll}\text { 4.1 Basic Design of the Microscope } & 117\end{array}$

4.2 Resolution of the Electron Microscope 125 
4.3 Calibration of the Microscope 133

4.4 Specimen Preparation Methods 135

4.5 Special Stages for the Electron Microscope 140

$\begin{array}{ll}\text { 4.6 Trends in Microscope Design } & 141\end{array}$

4.7 Guide to Further Reading 143

5. Electron Microscope Image Contrast 145

5.1 Electron Scattering 145

5.2 Absorption and Phase Contrast 152

5.3 Diffraction Contrast $\quad 159$

5.4 Fringe Contrast from Boundaries, Faults, etc. 176

5.5 Contrast from Continuous Strain Fields 192

5.6 Guide to Further Reading 204

$\begin{array}{lr}\text { 6. X-ray Topography } & 207\end{array}$

6.1 Experimental Methods in X-ray Topography 208

6.2 Contrast of Images in X-ray Topography 222

6.3 Some Applications of X-ray Topography 238

6.4 Guide to Further Reading 245

7. Field-Ion Microscopy 248

7.1 Design and Operation of the Microscope 248

7.2 Principles of Image Formation 253

$\begin{array}{lll}7.3 & \text { Field Evaporation } & 256\end{array}$

$\begin{array}{lll}7.4 & \text { Practical Problems } & 257\end{array}$

7.5 Applications of Field-Ion Microscopy 258

$\begin{array}{lll}7.6 & \text { Point Defects } & 260\end{array}$

$\begin{array}{lll}7.7 & \text { Dislocations } & 262\end{array}$

$\begin{array}{lll}7.8 & \text { Planar Interfaces } & 264\end{array}$

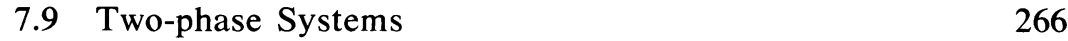

$\begin{array}{ll}7.10 \text { Surface Studies } & 268\end{array}$

$\begin{array}{ll}7.11 \text { Conclusion } & 268\end{array}$

7.12 Guide to Further Reading 269

8. Unconventional and New Techniques 270

$\begin{array}{ll}8.1 \text { Field-emission Microscope } & 271\end{array}$

8.2 Thermionic and Photoemission Microscopy 274

8.3 Energy-analysing and Energy-selecting Microscopes 277

8.4 Mirror Electron Microscopy 284

8.5 Scanning-transmission Microscope $\quad 286$

8.6 Guide to Further Reading 296

$\begin{array}{ll}\text { Index } & 297\end{array}$ 


\section{Preface}

Microscopy is a craft that requires an 'on-line brain'. This is why it is one of the most satisfying activities available in the experimental sciences. Because it is a craft, it demands a high level of skill in preparing the specimens and in adjusting the instruments to extract the fullest information; but more important is the knowledge that the experimenter is continually using: his familiarity with the principles and practice of the instrument itself so that its control becomes second nature and his understanding of the theory of image formation in the microscope, which enables him to select the conditions appropriate to the problem-and to be confident of his results.

But however fascinating the practice, the raison d'être of microscopy is that it is a tool for investigating the microstructure of materials. The establishment over many decades of some of the relationships between the microstructure and the macroscopic properties of materials has had profound consequences in scientific understanding and in industrial practice. Increased understanding of traditional materials has led to their safer, better or cheaper use; new types of material have been developed with spectacular mechanical or electrical properties, and better knowledge has meant better control of the production of both materials and components. During the period of this advance, both energy and raw materials were relatively abundant and cheap; this era has ended and the efficient use of such resources is now imperative.

A formidable array of techniques of microscopy is now available to the investigator. Unfortunately a technical and theoretical description of these methods is often only to be found in very advanced forms, such as original papers or monographs aimed at the experienced professional scientist. Our aim in this book has been to write a balanced account of all the important advanced methods of microscopy, beginning at a level convenient for undergraduates. In the main chapters we have covered scanning and transmission electron microscopy, the various microanalytical techniques, X-ray topography and field-ion microscopy. In the final chapter we have treated more briefly some rather rare methods, such as photoemission microscopy, and have endeavoured to survey the most 
recent developments, some of which may become important in the future. We have discussed the principles and construction of each instrument, have treated the theory of contrast from various types of specimen in some detail and have given examples of the application of each technique, chosen to cover a wide range of materials and types of problem. We hope that we have answered two rather different questions: what can this instrument be used for, and, which technique is best for this particular problem? We have not attempted to write a buyer's guide or operator's manual-although prospective buyers or operators should know most of the contents of this book - and so we have ignored such points as the idiosyncrasies of instruments made by particular manufacturers, purely technical problems such as the design of special stages, or matters of historical interest only such as the once severe problem of specimen contamination in the electron microscope (which has now been largely eliminated by better vacuum technology). SI units are used throughout, with the addition of the electron volt and the torr.

Although optical microscopy is an important method for the study of microstructure it will doubtless be abundantly familiar to almost every reader of this book and, moreover, it is already well covered in textbooks at a number of levels. We have therefore excluded optical microscopy from our treatment, along with various non-imaging methods of X-ray, electron or neutron diffraction. However, chapter 1 contains a brief review of the microstructural information available from these techniques and their advantages and limitations in order that the remaining chapters may be appreciated in a proper context.

The book as a whole is intended to be appropriate for a second- or third-year undergraduate course in materials science, metallurgy, physics or engineering science. We have assumed a basic knowledge of the structures and microstructures of materials, of common types of defects in crystalline materials and of elementary diffraction (essentially Bragg's law and the reciprocal lattice construction). The mathematical level required is generally no more than school-level calculus and algebra with the addition of some vector algebra and some elementary statistics and Fourier analysis; a knowledge of the last two topics is not central to comprehension of the book as a whole. The level of knowledge assumed in different chapters, and suggestions for preliminary reading for the 'non-standard reader' are discussed in section 1.3. Of course, a consistent level of treatment leads to an inconsistent level of rigorous interpretation simply because some phenomena are more complex than others. Thus, we have derived the basic equations of electron diffraction in chapter 5 , but in chapter 6 the corresponding theory for X-ray diffraction has only been qualitatively explained by analogy with the electron case. We were unwilling to assume familiarity with vector calculus, Maxwell's electrodynamic field equations and some slightly tricky manipulation of Fourier series, and moreover, the importance of the subject to a book at this level would not justify such complexity. However, the treatment of both electron and X-ray diffraction is in terms of the dynamical theories, without which the comprehension of electron microscopy contrast be- 
comes superficial and that of X-ray topography almost non-existent. We hope that we have succeeded in making these theories accessible to the undergraduate.

We have had two other classes of reader very much in mind. One is the graduate in some other scientific discipline who finds himself doing research or development work in a university, national laboratory or industrial laboratory and becomes involved in the study of the microstructure of materials. He should find here a reasonably rapid conversion course on the advanced observational techniques, that will enable him to select those applicable to his own field. The other is the graduate in materials science, metallurgy or a related field who finds himself (in, say, an industrial laboratory) expected to work on or even take charge of advanced equipment for microscopy with which he had only a passing acquaintance as a student. The equipment described in this book is expensive; the cheapest is probably one of the simple X-ray cameras which with its X-ray unit would cost about two years' salary of the new graduate, while the dearest (the high-voltage electron microscope) might be purchased with his lifetime's salary if he were particularly successful. To avoid wasting the resources that these instruments represent they must be used intelligently, and we must emphasise that the best and most meaningful results are obtained from modern microscopes only when the experimenter thoroughly understands his problem, his instrument and the theory of its operation.

It is a pleasure to express our gratitude to all those who have helped us in various ways in the preparation of this book. First, we should like to thank those who taught us and stimulated our own interest in the science and art of microscopy, in particular Professors P. B. Hirsch, F. R. S. and J. W. Christian, F. R. S. and Drs M. J. Whelan, A. Howie and L. M. Brown. Next, we are happy to acknowledge discussions with many colleagues on various aspects of the techniques described in this book and would especially mention Drs G. R. Booker, C. van Essen, J. Miltat and G. Slodzian. We are most grateful to those who have provided us with photographs or diagrams illustrating various aspects of their work; this has meant that we have been able to draw on a much greater variety of examples than would otherwise have been possible. Specific acknowledgements appear in the figure captions for these illustrations. We should like to thank Mr C. G. Lovatt for valuable assistance with the preparation of the photographs and also the many Warwick University students of materials science, physics and engineering science on whom much of the contents of this book has been tested. Finally, we now understand very clearly why authors invariably thank their wives for their assistance and forbearance. We likewise thank them.
University of Warwick, Coventry
D. K. BoweN
January 1975
C. R. HALl 